\title{
Intensification of melioration through decreasing maintenance load on irrigation canals
}

\author{
Abdrazakov F.K*1, Rukavishnikov A.A. ${ }^{1}$, Povarov A.V. ${ }^{1}$,Trushin Y.E. ${ }^{1}$ \\ ${ }^{1}$ Saratov State Vavilov Agrarian University, Saratov, Russian Federation
}

\begin{abstract}
The article presents current problems of irrigation canals. We list research methods while specifying the methods and work processes used. We have schematically depicted and theoretically described the necessary operations for the construction, reconstruction and repair of irrigation canals. Additionally, we have substantiated the economic losses arising from using concrete facing materials, and proposed modern facing materials designed to solve the main issues of irrigation canals. The article demonstrates the results of work on laying concrete canvas and geosynthetic materials. We have described and clearly classified the proposed facing materials and systemically listed advantages and disadvantages of modern facing materials compared to standard concrete canvas. On the basis of the study, the technological intensification of melioration was presented by reducing the construction and maintenance load on irrigation canals. We have theoretically and visibly demonstrated the efficiency of proposed materials and mathematically proven the intensification of melioration by reducing the maintenance load on irrigation canals. The findings indicate that the use of the proposed materials should increase the performance of irrigation grids, as well as reduce the maintenance load on them.
\end{abstract}

\section{Introduction}

Irrigation canals are the main transporting element of irrigation water throughout the irrigation system. Each branching of the canals is tied to a specific place of irrigation; therefore, when one of the branches fails, a certain irrigated area will not be moistened fully or will not receive irrigation at all. Accordingly, maintaining canals and keeping them up and running is a top priority. The aim of our study is to determine rational options for intensification of melioration by reducing the maintenance load on irrigation canals.

\section{Methods}

During this study, we have used the method of empirical cognition, which served as a synthesis for theoretical analysis of literature using deductive method. The theoretical method included reference, abstracting and quoting general and special scientific works in the field. In the work we have used mathematical and statistical methods to obtain and establish quantitative dependencies between the studied phenomena. The mathematical method included data registration. The statistical method included the determination of the averages of the indicators obtained, comparing and receiving quantitative or qualitative dependence of the process under study.

\section{Results}

As we know, irrigation network canals are constantly in need of maintenance, to ensure stable transportation ability and deliver the necessary volumes of irrigation water. Without a proper amount of constant and seasonal maintenance operations, a canal can fail and thus not be able to supply pre-planned volume of crops from irrigated areas [1-4].

We will consider what operations are necessary for stable functioning of an irrigation canal (see figure 1).

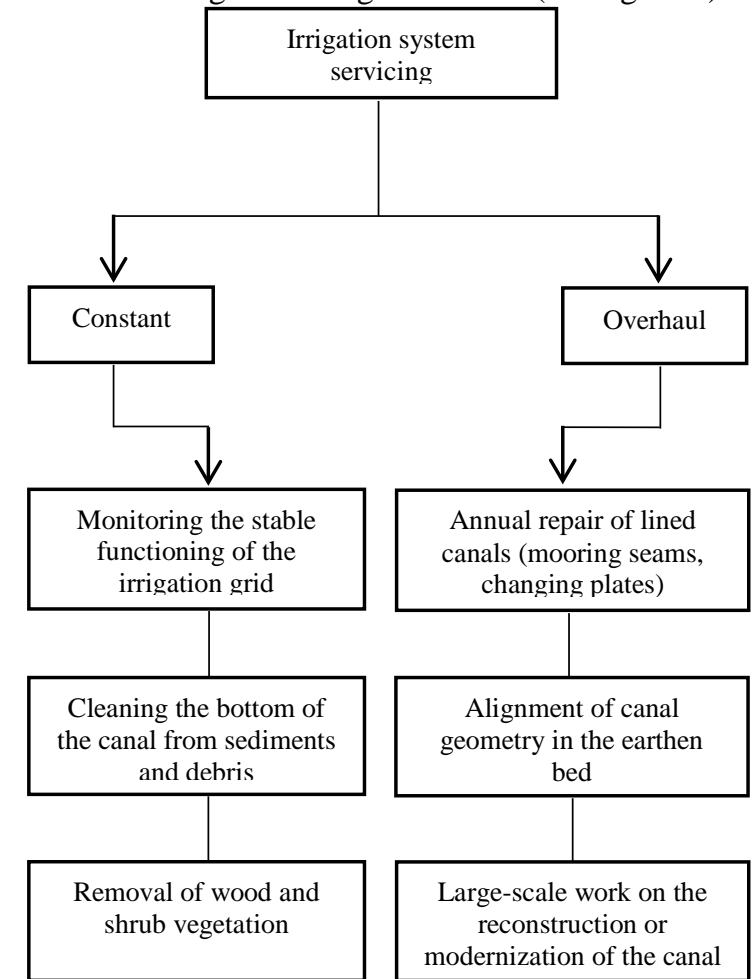

Fig. 1. - Irrigation system servicing operations.

The operations described above are mandatory for irrigation canals in the earthen and lined bed. It is worth noting that these operations require the availability of specialized equipment, as well as direct and secondary

\footnotetext{
* Corresponding author: abdrazakov.fk@mail.ru
} 
costs for a number of works [5, 6]. As innovative technologies and materials develop every year, it is possible to apply them in the melioration industry to improve the irrigation grids and intensify the operations of the irrigation grid.

Regarding the objective facts above, we propose to use better materials for irrigation canal facing that will thoroughly reduce the maintenance of the irrigation grid. Such materials are concrete canvas and composite geosynthetic materials for the lining of the canal. At the same time, the greatest preference in technical terms is given to the concrete canvas. These materials are presented in figures 2.1 and 2.2. [9-12].

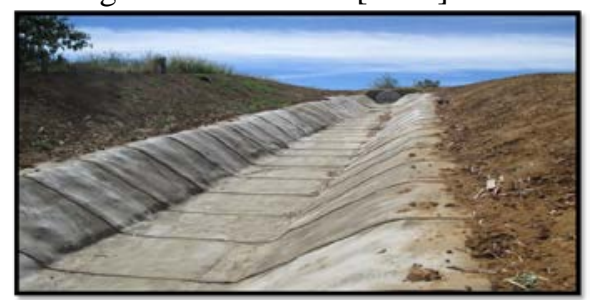

Fig. 2.1. - Concrete canvas-lined irrigation canal.

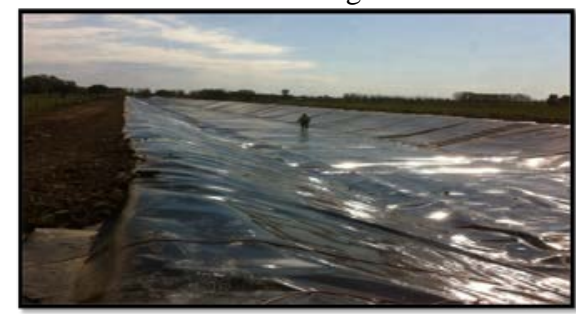

Fig. 2.2. - Geosynthetic membrane-lined irrigation canal.

Let us consider the classification for each of the proposed materials to make well-informed analysis. Geosynthetic materials are materials that come in forms of technical fabrics, meshes, rolls of waterproofing materials, as well as their combinations in the form of geocomposites or cellular frames.

Such materials have a wide range of applications, one of which is waterproofing. Let us give a classification of these materials (see figure 3 ).

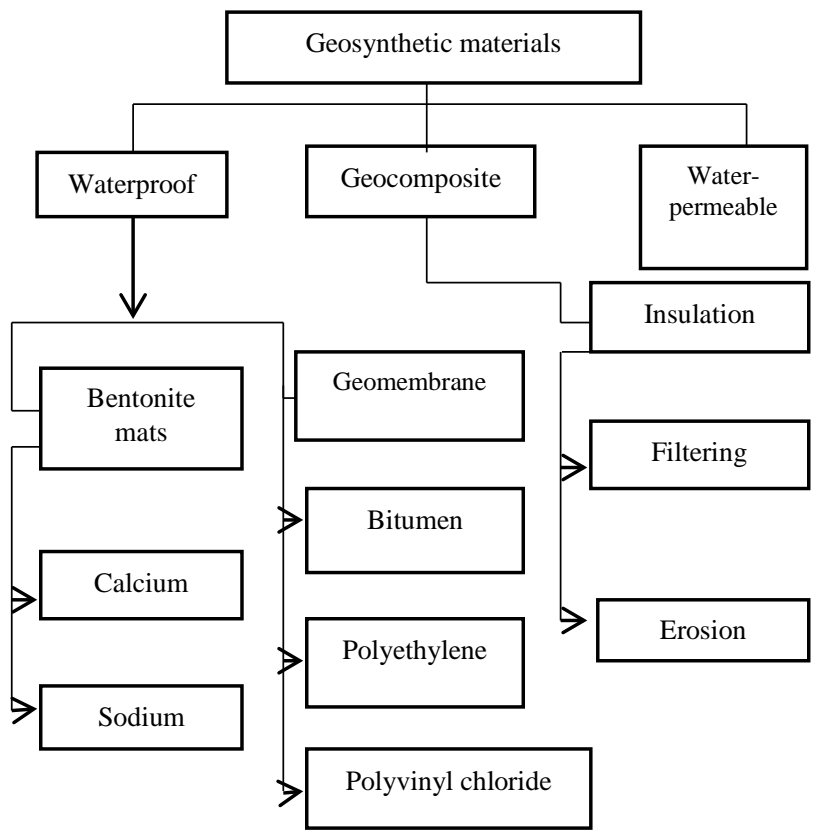

Fig. 3. - Classification of geosynthetic materials.
This picture shows the classification of waterproofing materials, water-permeable materials have been mentioned because they are part of geosynthetic materials, but not part of our study.

The advantages of this material are its durability and cost-effectiveness.

For additional information about this material, we will give a visual image of geosynthetic material on the example of a geocomposite version (see figure 4).

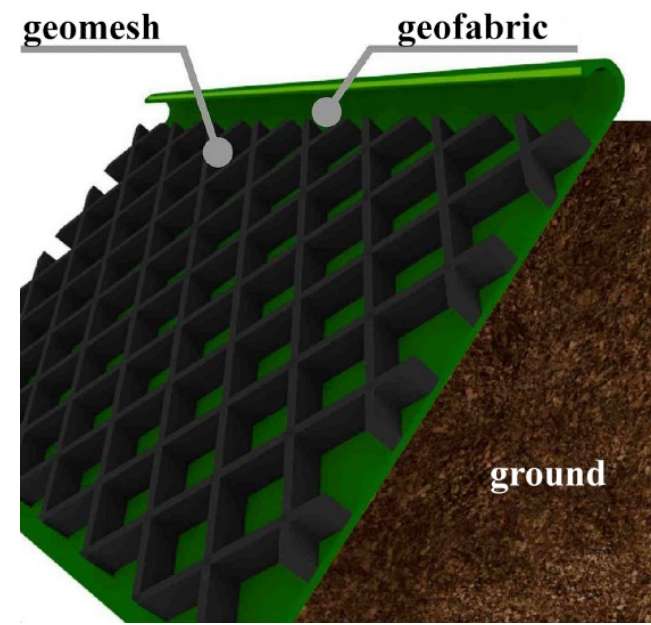

Fig. 4. - Example of a geocomposite material.

This picture clearly shows several levels of different geosynthetic materials that form a geocomposite. The technical meaning of this material is to avoid the loss of water resources in all possible ways, if specificity regarding irrigation canals is necessary.

Now we will consider the next innovative material recommended for use as a facing solution for irrigation canals. Such as the concrete canvas.

The concrete canvas consists of:

- fibrous surface, absorbing the humidity;

- matrix that strengthens the fibers;

- dry concrete mixture;

- waterproof polyvinyl chloride pads.

We will give a classification of concrete canvases in Figure 5.

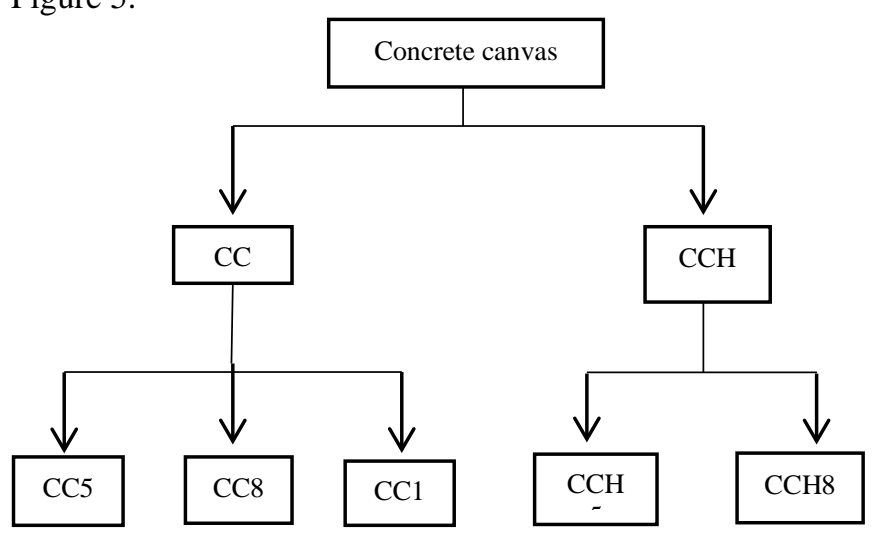

Fig. 5. - Classification of concrete canvases.

Concrete canvases have their own unique classification, the abbreviation CC means concrete canvas, and the index standing next to it denotes the thickness of the material. In the case of the name $\mathrm{CCH}$, 
the abbreviation means a concrete canvas with an additional hydraulic pad.

By analyzing the classifications given, you can detect the relationship between these materials. This judgment is supported by the polyvinyl chloride pad relating to bentonite mats and the general attitude to geocomposite materials through an insulating anti-erosion orientation [13].

Now we will perform a comparative analysis of the materials under study in Table 1 . The analysis was carried out through a theoretical study of the concrete canvas with the CC8 brand and composite geosynthetic materials based on bentonite mats and all types of geomembranes. The study was directed at irrigation canals.

Table 1. Comparative analysis of concrete canvas and geosynthetic materials

\begin{tabular}{|c|c|c|}
\hline Indicator & Concrete canvas & $\begin{array}{l}\text { Geosynthetic } \\
\text { materials }\end{array}$ \\
\hline Cost, rub/m² & 3000 & 500 \\
\hline $\begin{array}{l}\text { Equipment } \\
\text { requirements }\end{array}$ & Minimum & Minimum \\
\hline Number of workers & Minimum & Minimum \\
\hline $\begin{array}{l}\text { Coating speed, } \\
\text { m²/day }^{2}\end{array}$ & 800 & 800 \\
\hline $\begin{array}{l}\text { Resistance to cracks } \\
\text { and ruptures }\end{array}$ & High & Average \\
\hline Water resistance & Low & Low \\
\hline Frost resistance & High & High \\
\hline Fire resistance & High & None \\
\hline Tightness of seams & High & Low \\
\hline Strength & High & Average \\
\hline Longevity, years & 50 & 50 \\
\hline Chemical resilience & High & High \\
\hline $\begin{array}{l}\text { Material mobility } \\
\text { after laying }\end{array}$ & None & Allowed \\
\hline Puncture strength & High & Low \\
\hline $\begin{array}{l}\text { Resistance to roots } \\
\text { (vegetation) }\end{array}$ & High & Average \\
\hline
\end{tabular}

The comparative analysis has demonstrated that they are a good option to use for increasing the productivity of the irrigation grid.

We will analyze how intensive operations become after the introduction of modern materials and technologies on the example of concrete canvas (see Figure 6).

Based on the research, there is a reduction in financial and technical operations with the improvement of the quality of the base. It is also worth noting that when using a concrete canvas, the need for largemechanized equipment is reduced by $90 \%$, as the installation process does not require it at all, and the maintenance will call for the use of small mechanized equipment-"bobcat".

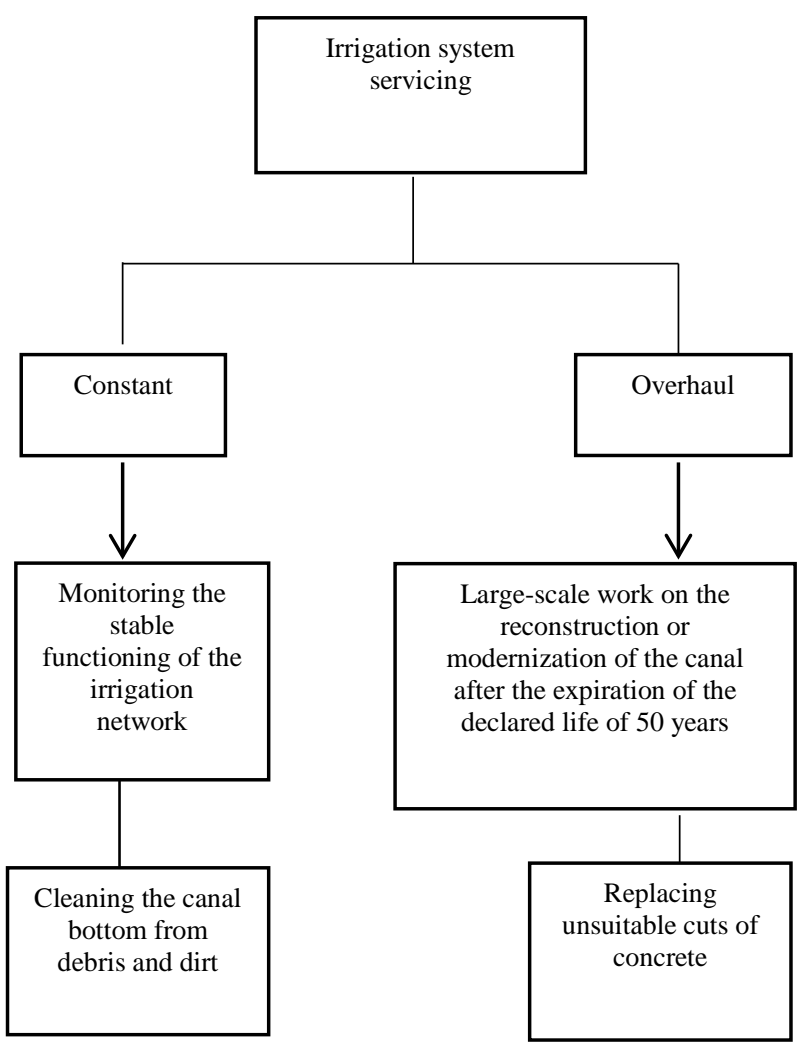

Fig. 6. - Irrigation system servicing operations after intensification.

The mathematical justification for the intensification of melioration by reducing the maintenance load on irrigation canals.

The mathematical meaning of this intensification is to prove the effectiveness of the proposed solution in the form of technological operations.

We have two facing materials $\mathrm{A}$ and $\mathrm{B}$, which have differences in cost, installation costs and maintenance of the irrigation canal lined with one of the materials presented.

Note that:

$$
A>B \text {, }
$$

where A is the cost of a concrete canvas; B is the cost of concrete facing slabs.

For greater informativeness, we will add the cost of each material (in rubles) to the formula:

$$
A>B=3000>1500
$$

When using material $\mathrm{B}$, about 6 maintenances need to be carried out to maintain the canal in order for it to function in a stable manner.

$$
B_{T}=q_{1}+q_{2}+q_{3}+\left(q_{4}+q_{5}+q_{6}\right)_{x}
$$

Where $B_{T}$ is the irrigation canal maintenance technology using material $\mathrm{B} ; q$ are technological operations that can take place regardless of each other except in some cases.

In turn, the use of material A reduces the maintenance operations.

$$
A_{T}=q_{1}+q_{2}+\left(q_{3}+q_{4}\right)
$$


where $A_{T}$ is the technology of servicing the irrigation canal using concrete canvas.

From this we can deduce the following pattern: the use of concrete canvas, or material $A$, reduces the technology of irrigation canal maintenance by $1 / 3$, this is the intensification of melioration.

Then, the following note will be mathematically true:

$$
A_{T}=\frac{\left.\left(q_{1}+q_{2}+q_{3}+q_{4}+q_{5}+q_{4}\right)\right]}{1_{15}}=q_{1}+q_{2}+\left(q_{2}+q_{4}\right)
$$

where the denominator of fraction acts as a reduction of the entire process of construction or maintenance of the irrigation canal.

It is also worth noting that the cost of building a canal covered with concrete canvas is much less than that of one with concrete facing and justifies the initial cost of material A in the future.

It follows that:

$$
A_{T}<B_{T}
$$

where $A_{T}$ acts as the total cost of maintenance of the irrigation canal covered with concrete cloth; $B_{T}$ acts as the total cost of maintenance of the irrigation canal covered with concrete facing.

Accordingly, we obtain the following pattern:

$$
A+A_{T}<B_{T}+B
$$

\section{Conclusions}

Thus, we can state that the use of modern materials can improve the performance of the irrigation canal, as well as reduce the maintenance load on irrigation canals, both technically and financially. At the same time, the required volume of irrigation water will be supplied in a timely manner. The illustrations presented and the mathematical justification proves that the technology we have proposed to intensify melioration, by reducing the maintenance load on irrigation canals, is and should be used in melioration. The concrete canvas is more applicable for installation in irrigation canals because of its physical properties, simplicity of maintenance and service, and the fact that it prevents vegetation growth, which makes it optimal and effective.

\section{References}

1. F.K. Abdrazakov, A.V. Pomorova, S.V. Zatinatsky, A.V. Povarov, A.A. Halmetov, "Basic Requirements of Investment Planning Calculation Efficiency in Hydraulic Engineering”, Journal of Engineering and Applied Sciences, no. 12 (5) 1288-1295 (2017).

2. F.K. Abdrazakov, A.A. Rukavishnikov, A.A. Khalmetov, A.V. Povarov «Problems of Irrigation Canals and Modern Methods of Their Technical Improvement due to Innovative Concrete Materials and Technologies» International Symposium "Engineering and Earth Sciences: Applied and Fundamental Research" dedicated to the 85th anniversary of H.I. Ibragimov (ISEES 2019) 375-378 (2019).

3. F.K. Abdrazakov, A.V. Povarov, D.A. Solov'yov, Yu. Ye. Trushin, A.A. Khalmetov, "The study of the process of face milling cutter work by performing service and repair works at irrigation canals”, ARPN Journal of Engineering and Applied Sciences, vol. 11 9613-9621 (2016).

4. M.A. Bandurin, I.F. Yurchenko, V.A. Volosukhin, V.V. Vanzha, Ya.V. Volosukhin, "Ecological and economic efficiency of diagnostics of technical condition of water supply facilities of irrigation systems”, J. Ecology and Industry of Russia, vol. 22 (7) 66-71 (2018).

5. M.A. Bandurin , V.A. Volosukhin, V.V. Vanzha, "Technology for Water Economy Monitoring of Technical State of Closed Drainage on Irrigation Systems”, Materials Science Forum, vol. 931 214218 (2018).

6. Yu.M. Kosichenko, O.A. Baev, A.V. Ishenko, "Modern methods of dealing with filtration in irrigation systems»”, Engineering journal of Don, vol. 3 85-97 (2014).

7. Yu.M. Kosichenko, O.A. Baev, A.Yu Garbuz, "Features of permeability calculation for concretelined facing with sealed seams taking into account the ground permeability”, Vestnik MGSU, vol. 13, iss. 5 (116) 633-342 (2018).

8. F.K. Abdrazakov, T.A. Pankova, S.V. Zatinatsky, S.S. Orlova, Y.E. Trushin, "Increasing Efficiency of Water Resources Use in Forage Crops Irrigation”, International Journal of Ad-vanced Biotechnology and Research, vol. 8 283-293 (2017).

9. F.K. Abdrazakov, O.V. Mikheeva, A.V. Povarov, S.V. Zatinatsky, Yu. Ye. Trushin «The research of qualitative indicators of gas pipelines during the operation», Journal of fundamental and applied sciences, vol. 9 722-731 (2017).

10. F.K. Abdrazakov, A.V. Povarov, D.A. Solov'yov, Yu. Ye. Trushin, A.A. Khalmetov «The study of the process of face milling cutter work by performing service and repair works at irrigation canals» ARPN Journal of Engineering and Applied Sciences 11(16) 9613-9621 (2016).

11.F.K. Abdrazakov, A.V. Pomorova, M.A. Shchenyatskaya, O.V. Litvishko «Organizational partnership for building, reconstruction and capital overhaul of hydrotechnical structures» International Business Management 9(6) 1163-1168 (2015).

12. F.K. Abdrazakov, A.A. Rukavishnikov «Elimination of unproductive losses of water resources from the irrigation network through the use of modern facing materials» The Agrarian Scientific Journal, vol. 10 56-61 (2019).

13. F.K. Abdrazakov, A.A. Rukavishnikov, "Intensification of land reclamation production due to improvement of technologies of reconstruction and construction of irrigation canals of Saratov region”, The Agrarian Scientific Journal, vol. 10 48-51 (2018). 